\title{
EyeFoods: A Food Plan for Healthy Eyes
}

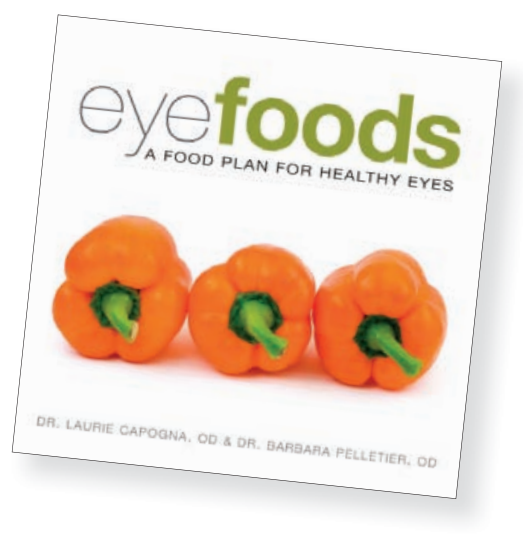

BY PAUL CHRIS, OD

$n$ October 12th, 2001, the
results of a major clinical trial sponsored by the U.S. based National Eye Institute (NEI) were released to the public. The findings from this nationwide clinical trial, which became known as AREDS (Age Related Eye Disease Study), demonstrated that high levels of antioxidants and zinc can significantly reduce the vision loss associated with age related macular degeneration (AMD).

According to the NEI press release at the time: "Scientists found that people at high risk of developing advanced stages of AMD, a leading cause of vision loss, lowered their risk by about 25 percent when treated with a high-dose combination of vitamin C, vitamin E, beta-carotene, and zinc. In the same high risk group - which includes people with intermediate AMD, or advanced AMD in one eye but not the other eye - the nutrients reduced the risk of vision loss caused by advanced AMD by about 19 percent. For those study participants who had either no AMD or early AMD, the nutrients did not provide an apparent benefit."

This landmark study started a surge of interest in nutrition and ocular health. In the last ten years, dozens of studies have shown the importance of other nutrients in the prevention of vision loss. In 2004, the Veterans LAST Study (Lutein Antioxidant Supplementation Trial) demonstrated that visual function was improved in a group of patients with AMD using a daily dietary supplementation of $10 \mathrm{mg}$ of lutein, a carotenoid found in dark green leafy vegetables, egg yolk and other food sources. A 2011 study reported in Archives of Ophthalmology stated that a dietary intake of omega-3 fatty acids and fish significantly reduced the risk of developing AMD in a group of nearly 40,000 female health professionals.

Other studies have shown that vitamin $\mathrm{D}$ deficiency is associated with retinopathy in children and adolescents with type 1 diabetes; that a combination of vitamin B-6, vitamin B-12, and folic acid may protect women against AMD; diets that included excessive amounts of sugars and refined carbohydrates increased the risk of cortical cataracts over a ten year period; that lutein may protect the eyes from the harmful effects of long-term computer display light exposure and improve contrast sensitivity; that the consumption of processed meat, not red meat, is associated with a higher rate of heart diseases and diabetes; and many more similar findings relevant to eye health.

In September 2006, the NEI- sponsored Age Related Eye Disease Study 2 (AREDS2) started and is designed to look at the effects of high oral supplementation of lutein, zeaxanthin and omega-3 fatty acids (EPA/DHA) for the treatment of AMD and cataracts. It is also looking at the role of a reduced zinc concentrations and the elimination of beta-carotene from the original AREDS formula. Scientists are eagerly awaiting the results of this study which will be released in 2013.

Understanding the importance of nutrition in ocular health is now an essential part of an optometrist's role in providing patients with prevention and treatment strategies to preserve and protect vision and eye health.

And now, a newly published book that explores the role of foods in maintaining healthy eyes has been written by two Ontario optometrists, Laurie Capogna, OD, and Barbara Pelletier, OD. Their book, EyeFoods: A Food Plan for Healtby Eyes, is an excellent nutrition and eye health primer for optometrists, but an even more important resource for patients and the public. Drs. Capogna and Pelletier have done an extensive review of the existing scientific literature and put together an easy to read and highly informative book that can educate patients about nutrition, the eye and vision, and the age related eye diseases that we are all prone to.

The book is written in three parts. Part One: The Basics has two chapters. Chapter One: Eye Health and Disease looks at the nature 
of AMD, cataracts, dry eye syndrome and eyelid disorders. Chapter Two: Eye Nutrients looks at the nature and role of antioxidants, omega-3 fatty acids, fibre and the various relevant vitamins and minerals. In part two, Chapter Three: Eyefoods explores the important foods, called eyefoods, which contain the essential nutrients for eye health. Chapter Four: Lifestyle and General Health looks at the lifestyle issues that must also be addressed when dealing with any health issue, including smoking, UV exposure and exercise. The final chapter in Part Three: The Plan lays out weekly targets for the consumption of eyefoods, some valuable ideas about serving sizes, and guidelines on the lifestyle factors that are as critical to eye health as good nutrition.

With colourful photographs, starting with the smart cover design, well constructed charts and diagrams, and an easy to read font, the book is a treasure trove of science based information for patients about nutrition and ocular health. There are several chapter summaries, an excellent glossary, a comprehensive list of references and a detailed index for searching through the material. The nutrition information is accurate and up-to-date. Their food tips, meal ideas and quick and easy recipes are great.

The authors have not shied away from challenging Canada's Food Guide. On page 101, they point out that the Food Guide recommends that half of all grain choices be whole grain foods.
The truth is that there really is no place in our diet for any refined grains and Drs. Capogna and Pelletier appropriately recommend eliminating refined grains entirely from the diet. If there is any criticism to make of the contents of the Eyefoods book, it may be that they have not gone far enough in challenging Canada's Food Guide to which they make numerous references. The 2007 version of the guide, despite its improvement over the 1992 version, has been criticized as placing too much emphasis on grains, dairy products and processed vegetable oils. This over emphasis is a result of the considerable involvement of the food industry, without evidence-based support, in the guide's content. Many scientists believe that our western grain and dairy based diet is a major cause of our epidemics of obesity, diabetes and related chronic diseases.

However, the Eyefoods book is an excellent guide to nutrition and ocular health and I would recommend that optometrists make it available in their offices for their patients.

\section{Dr Paul Chris is the Executive} Director, Vision Institute of Canada and a founding director of the Ocular Nutrition Society.

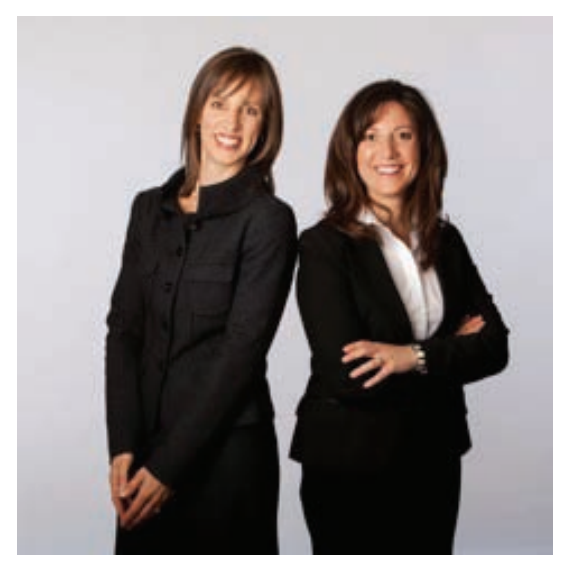

The story behind the book Eyefoods: A Food Plan for Healthy Eyes

\section{Dr. Laurie Capogna, OD \& Dr. Barbara Pelletier, OD}

In today's optometric practice, we face several challenges on a daily basis. Our patients are increasingly educated. Sometimes their source of information is not necessarily reputable and we need to set the facts straight. It is our role to be more knowledgeable than our patients on several topics, including the role of nutrition for eye health. We get questions regularly regarding different supplements available at health food stores and about what to eat to help maintain healthy eyes.

Three years ago we decided to use our common passion about healthy living and optometry to create a tool to answer our patients' questions and to educate the public about what they could do to help preserve their vision. At the time we didn't know what form this tool would take, or for that matter, exactly what information it would include. However, we did know that new studies were continually emerging regarding the connection between nutrition, lifestyle and the prevention of eye disease. We also knew that in order to pass this information along we'd have to present it in a simple, practical and fun way.

After attending several optometry conferences that focused on nutrition and ocular health, we realized that there was 
an overwhelming amount of information that we needed to understand before we could educate our patients thoroughly. We decided to review the literature on nutrition and eye health, summarize it and come up with an easy-to-follow plan for our patients. We soon realized that this was going to be an enormous task. After a year of research, a year of analysis, recipe search and plan developing and another year of editing, consulting, reviewing, translating and book design, Eyefoods: A Food Plan for Healthy Eyes was born.

Our mission is to empower our patients and the public with the knowledge they need to prevent eye disease and vision loss.

We launched Eyefoods at the OAO Symposium in April and introduced it to the attendees of the CAO Congress in Winnipeg in July. The support of our profession was overwhelming. Many optometrists told us this book fills a need for their patients and saves chair time. We have also had an enthusiastic response and support from various ophthalmologists, and from Dr. Larry Alexander, Dr. Melton and Dr. Thomas.

We want to thank all optometrists who have showed interest in eyefoods and are contributing to spreading the message to their patient base. Our goal is simple: help patients realize they can make a difference in their ocular health with easy everyday choices.

This fall we will be speaking at the CNIB conference in Toronto and exhibiting at the Alberta Association of Optometrists Conference, the Association des optométristes du Québec, the Vision Institute Conference and the American Academy of Optometry Conference.

Eyefoods is available in both English and French. For more information on Eyefoods or to order the book please visit www. eyefoods.com.
A fully independently owned optometry practice in the central business district of Rockhamptom, Queensland, Australia is being offered for sale. Established 19+ years. Over 30,000 patient records. This practice offers an established and attractive income together with a chance to reside in a relaxed and enjoyable environment and have a great lifestyle. This independently owned practice offers full-scope services to our clients.

This is a great opportunity to own and operate your own practice without the unrealistic budgets set down by the corporates. The vendors can offer a lease of the premise or you have the opportunity to purchase the entire building.

Please contact me by email rockyoptical@cqnet.com.au. ORTELEPHONE 0417609624

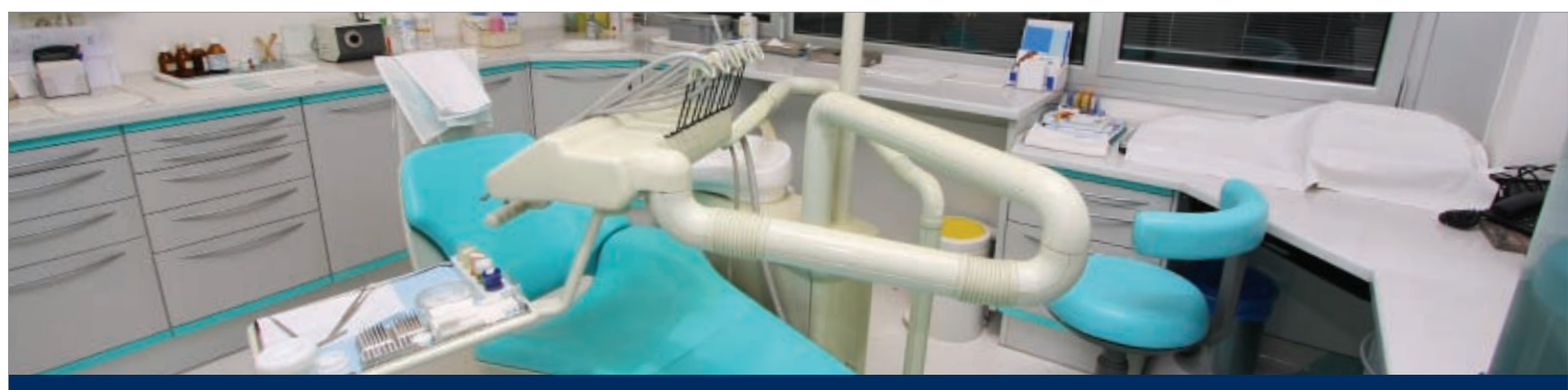

\section{Acquire The Equipment You Need Through the Leverage of Leasing}

MORE AND MORE, new and experienced practices leverage the financing power of leasing. We provide innovative and flexible equipment financing solutions to businesses \& practices seeking a competitive advantage.

We have reps in your area specialized in Healthcare Lease Financing, contact us today to save up to $\$ 200$ off a new lease:

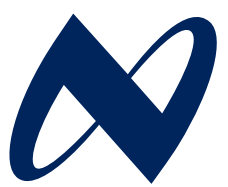

NATIONAL LEASING

\section{8-599-1966 www.nationalleasing.com}

